\title{
Optimal Conservation Programs, Asymmetric Information and the Role of Fixed Costs
}

\author{
Carmen Arguedas • Daan P. van Soest
}

Accepted: 28 February 2011 / Published online: 17 April 2011

(C) The Author(s) 2011. This article is published with open access at Springerlink.com

\begin{abstract}
An increasing number of environmental protection programs offers financial compensation to farmers in exchange for conservation services. Incentive-compatible contracts can be designed to mitigate excess compensation, but the extant literature suggests that outcomes are always second-best so that other instruments (such as conservation auctions) may be preferred. We argue that the claim regarding the first-best solution never being incentive-compatible is correct if all conservation costs are variable in nature; if there are fixed costs too, the first-best compensation scheme may be incentive-compatible after all. Given the relevance of fixed costs in conservation issues, we conclude that incentive-compatible contracts should be given a second chance as a policy measure to induce conservation.
\end{abstract}

Keywords Asymmetric information · Payments for ecosystem services · Mechanism design

JEL Classification $\quad \mathrm{D} 82 \cdot \mathrm{H} 23 \cdot \mathrm{Q} 57$

\begin{abstract}
We wish to thank two anonymous referees for their excellent comments, which helped us to substantially improve the paper's exposition and to sharpen the paper's policy implications. We would also like to thank Justin Dijk as well as participants at the 9th annual Bioecon conference for their comments and suggestions. Carmen Arguedas is grateful to the Spanish Ministry of Science and Innovation for their financial support (ECO2008-00510), and Daan van Soest wishes to acknowledge the financial support by "Knowledge for Climate" Program.
\end{abstract}

C. Arguedas

Departamento de Análisis Económico, Teoría Económica e Historia Económica, Universidad Autónoma de Madrid, Madrid, Spain

D. P. van Soest $(\varangle)$

Department of Spatial Economics and IVM, VU University Amsterdam, De Boelelaan 1105, 1081 HV Amsterdam, The Netherlands

e-mail: d.p.van.soest@vu.nl

D. P. van Soest

Department of Economics and CentER, Tilburg University, Tilburg, The Netherlands 


\section{Introduction}

Over the past two decades, many conservation programs have been set up that offer financial compensation to farmers in exchange for the provision of socially desired environmental services, which would not have been provided otherwise. Such activities include, among others, implementing measures to conserve soils or protect biodiversity. These so-called green payment programs have been implemented in developed and developing countries alike (see for example OECD 1997; Ferraro 2001 and Wunder et al. 2008), and usually take the form of contracts between a regulator (or donor) and individual farmers. Typically, these contracts specify the type and level of conservation activities the farmer is required to undertake on his land, as well as the amount of money he receives in compensation. Participation is in most instances voluntary, and hence the amount of money offered should at least cover the extra costs incurred.

In many instances (i) some farmers can provide conservation services at lower costs than others, and (ii) farmers have better information about the magnitude of these costs than the regulator (cf. Ferraro 2008). If the compensation payments are sufficiently generous, uniform (or one-size-fits-all) contracts can be very effective in inducing farmers to provide environmental services, but at the expense of generating substantial windfall profits. Whereas the payments only just cover the extra costs incurred by some farmers, those with cheaper conservation options obtain a net gain. Overgenerous payments are typically costly to the regulator either because the available funds are limited (in case of a fixed conservation budget) or because there are non-zero costs to raising funds (see for example Smith and Tomasi 1999). Hence, the regulator has a stake in separating the low-from the high-cost farmers.

In essence, this is a classical mechanism design problem, and over the past years many papers have been published that build on the seminal work of, among others, Mirrlees (1971), Groves (1973), Dasgupta et al. (1979), Harris and Townsend (1981), and Guesnerie and Laffont (1984). Early papers include Smith (1995) who analyzed how mechanism design theory could be applied to the US Conservation Reserve Program, aiming to return a specific amount of agricultural land to nature while minimizing the total amount of compensation payments paid; Smith and Tomasi (1995) who analyzed the problem of limiting pollution runoff from farm land when compensation payments are funded by means of distortionary taxation; and Wu and Babcock $(1995,1996)$ who looked at the problem of reducing polluting input use when land quality differs across farmers and where raising funds for compensation is socially costly. The general conclusion of the literature cited above is that offering a menu of contracts specifying management prescriptions and associated compensation payments can be more efficient than, for example, a uniform policy applicable to all farmers.

Despite the fact that these separating contracts can improve efficiency, they are hardly ever used in practice (Ferraro 2008). Two reasons may explain this lack of real-world application. First, the information requirements for the regulator are substantial. To design the contracts optimally, the regulator needs to gather information about all relevant economic characteristics of the various farm types. ${ }^{1}$ Second, the menu of contracts that would be offered in case of complete information (the so-called first-best menu of contracts) is typically not incentive compatible in the presence of information asymmetries. ${ }^{2}$ The reason is that, if low-cost farmers choose that contract from the first-best menu that is targeted at their type, they would

\footnotetext{
1 Relevant characteristics include those factors that affect farmers' opportunity cost of providing conservation services, such as their agricultural production functions, their land quality, the depth of the water table, the distance to (paved) roads, etc.

2 This complete-information (or first-best) menu is characterized as follows: (i) conservation levels imposed on the farmers are such that their marginal costs of providing conservation services are equalized (implying
} 
receive compensation that is just equal to the conservation costs incurred; their net benefits of participating would be zero. If instead these low-cost farmers choose the contract targeted at the farmers with higher conservation costs, they receive positive net benefits because they are able to offer the required amount of conservation services at lower average costs than the high-cost farmers. Therefore, the extant literature finds that an incentive-compatible scheme can improve welfare but that two inefficiencies always remain. The compensation payments to the low-cost farmers are strictly larger than the actual costs incurred (in other words, farmers of this type receive informational rents), while the conservation level required from the high-cost farmers is below the first-best level (Smith 1995; Smith and Tomasi 1995; Wu and Babcock 1995, 1996, and Moxey et al. 1999; see also Laffont and Tirole 1993). Because of this double inefficiency, the net benefits of designing incentive-compatible contracts are likely to be relatively small, and attention has shifted towards alternative instruments, such as for example procurement auctions for conservation contracts (cf. Ferraro 2008; LataczLohmann 2004; Latacz-Lohmann and Schilizzi 2006; Rolfe et al. 2009; Stoneham et al. 2003). ${ }^{3}$

In this paper we show that the double cost of separation inevitably arises only if all conservation costs are variable in nature; if there are fixed costs too, the first-best solution may be incentive compatible under asymmetric information. We extend the archetypical model of asymmetric information (see for example Moxey et al. 1999) by allowing only part of the conservation costs to vary with the amount of conservation services provided; we explicitly take into account that offering conservation services may require fixed set-up costs too. We do so by developing a simple model with two farmer types ${ }^{4}$ that differ with respect to the fixed and variable conservation costs they face, and where the regulator aims to maximize the net social benefits of conservation, taking into account the conservation benefits, the associated conservation costs (both fixed and variable), as well as the social costs of raising subsidies. ${ }^{5}$ When setting the fixed costs of both farmer types equal to zero we replicate the extant literature's standard result that the first-best solution fails to be incentive compatible (Smith 1995; Smith and Tomasi 1995; Wu and Babcock 1995, 1996, and Moxey et al. 1999). However, we also show that the regulator may be able to implement the first-best solution under asymmetric information if not all conservation costs are variable in nature-but only if farmers' fixed and variable conservation costs are negatively correlated.

Footnote 2 continued

that farmers with lower marginal costs offer more conservation services), and (ii) the compensation each farmer receives is exactly equal to the conservation costs she incurs.

3 Auctions have their own disadvantages too. To work well, auctions need to be collusion-free as well as simultaneous (rather than sequential, to prevent farmers' learning from the bids issued by their peers and from the behavior of the regulator); see Latacz-Lohmann and Schilizzi (2006). Preventing collusion in conservation auctions is difficult in practice because potential bidders tend to live in the same region and are likely to be able to identify their fellow participants in the auction. And auctions are inevitably sequential in nature, as a simultaneous auction of all conservation efforts in a country (or even in a region) is infeasible in practice. Hence, farmers can update their expectations about the regulator's reservation price, and hence the auction's outcome is not likely to be efficient. Therefore, whereas conservation auctions may be a superior instrument than (uniform) contracts, the efficiency gains actually obtained may be lower than predicted by theory.

4 Although there may be many types of farmers that differ with respect to the fixed and variable conservation costs, for simplicity we focus on the case where it is socially optimal to have just two of them implement conservation projects - the ones who can do so at least total cost (but see footnote 15).

5 This model is compatible with the principal being the government. Alternatively, we could have assumed simpler regulatory objectives, such as maximizing conservation benefits with a given budget, or achieving a certain aggregate conservation target at minimum cost. These alternative objective functions are more appropriate for cases in which the principal is an environmental NGO. Interestingly, all our conclusions remain valid under these alternative assumptions, as will become clear later on; see footnote 17. 
The result that fixed costs matter is surprising because they are essentially sunk costs. The menu of contracts offered is such that those farmers who should offer conservation services, do offer them, and they incur their fixed conservation costs independent of whether they choose the contract intended for their type, or the other one. So, all up-front investment costs are effectively sunk, but they still matter because they affect the amount of compensation payments targeted at each type. The payments consist of two parts: the compensation for the variable costs and for the fixed costs. If a farmer with low variable costs and high fixed costs (relative to the other type) chooses the contract targeted at the other type, he saves on his variable costs (because of the less stringent management requirements imposed). But if he thus declares himself to be of the high-variable cost type, he receives the compensation payment for that type's fixed costs. If this payment is sufficiently smaller than the compensation for the fixed costs of his own type, he prefers to truthfully reveal his type.

We therefore find that the first-best policy may be implementable under asymmetric information-but only if agents need to incur both fixed and variable costs when providing conservation services. This conclusion is relevant for both researchers and policy makers in the field of payments for ecosystem services because there is indeed a (non-negligible) fixed cost component associated with most —if not all — conservation projects (cf. European Commission 2005: 22, and Naidoo et al. 2006). Examples of such fixed conservation costs are the expenses incurred when setting up management plans, but also the costs associated with up-front investments without which conservation is not feasible (see for example Peerlings and Polman 2004; and ?). Using the example of biodiversity conservation, necessary up-front investments may include planting trees or hedgerows, and digging ponds or watering holes, to create a minimum amount of habitat for species to survive or to establish themselves in. But given that the necessary conditions for conservation have been created, the actual amount of biodiversity conservation achieved also depends on variable cost decisions like the types of crops cultivated, stocking rates, the amount of fertilizer and pesticides used, etc. Obviously, if farmers continue spraying their fields with traditional pesticides, conservation objectives are not achieved even if trees or hedgerows have been planted on the plot's perimeter. Reducing pesticide use increases species conservation but at increasing costs (in terms of agricultural revenue foregone). Farmers likely differ in the variable costs they face when providing conservation services - as is typically assumed in the literature-but they may well differ with respect to the associated fixed conservation costs too (Naidoo et al. 2006).

Farmers facing different fixed conservation costs is a necessary but not a sufficient condition for our model to be of real-world relevance. In fact, three additional assumptions (or conditions) need to be met. The two key assumptions used by the extant literature on green payments are that (all) conservation costs (i) are determined by external factors beyond the farmer's control, and (ii) are unobservable to the regulator (or observable only at prohibitively high expense). We retain these two assumptions, with the only caveat that they should hold for both cost components: the variable as well as the fixed costs. The third assumption is unique to our study: there should be instances of systematic relationships between the fixed and variable conservation costs, and in some of these the two cost components should be negatively correlated. While we do not rule out that there are other situations too in which these three assumptions/conditions are met, intuitively the most plausible situation is where the same factor causing farmers to have different variable conservation costs causes them to face different fixed costs as well.

With this idea in mind we surveyed the empirical literature on conservation programs, and discovered that if a particular set of circumstances is conducive to both high agricultural yields and nature conservation, the fixed and variable conservation costs of farmer types are likely to be negatively correlated. Take the example of nature conservation in arid regions. 
The lower the water table, the more expensive it is to (re)construct habitat for nature conservation (if only because one needs to dig deeper to create ponds or artificial watering holes for wildlife), but the variable (opportunity) costs of offering conservation services are lower because of the lower agricultural profits (see for example Garrido et al. 2006 for the case of Spain). Therefore, the regulator can infer that farmers with low variable conservation costs face high fixed costs, and vice versa. But if the spatial variation in groundwater availability is large enough so that it is prohibitively expensive to assess the per-hectare yields of every single patch of land farmers voluntarily offer to the conservation program, she does not know what level of fixed and variable costs each individual farmer faces (e.g., Martínez-Santos and Martínez-Alfaro 2010). This is just one example of the same factor (unobservable to the regulator, and exogenous to the farmer) affecting both the fixed and variable costs a farmer faces, and we found other circumstances too-hydrological factors, infrastructural patterns, and also nature itself.

The setup of this paper is as follows. We present the model in Sect. 2, and provide the solution to the complete information problem (that is, the first-best solution) in Sect. 3. In Sect. 4 we analyze whether the optimal contract under asymmetric information is uniform or separating, and we address the question under what circumstances the first-best solution is incentive compatible. In Sect. 5 we return to the issue of whether the same unobservable factor can systematically affect farmers' fixed and variable conservation costs. We present the examples hinted at in the previous paragraph, and we infer under what circumstances the first-best solution may be incentive compatible - and hence when compensation contracts may be the preferred conservation instrument. Section 6 concludes. All proofs are in Appendices A and B.

\section{The Model}

We follow the extant literature on incentive-compatible conservation contracts (e.g., Smith 1995; Smith and Tomasi 1995; Wu and Babcock 1995, 1996, and Moxey et al. 1999) and assume that conservation agents (or farmers) differ in the costs they incur for providing conservation services. Our model differs from this literature in just one respect: while the extant literature assumes that all conservation costs vary with the amount of services provided, we explicitly allow for the possibility that there are fixed conservation costs too, which may or may not differ between the various farmers (?). We follow Wu and Babcock (1995) and Moxey et al. (1999) in assuming that there are just two types of farmers, indexed $i=1,2$, where $n_{i}>0$ denotes the total number of farmers of type $i$. Each farmer can supply conservation services, $b \geq 0$. This activity generates both fixed and variable costs, denoted by $F_{i}$ and $c_{i}(b)$, respectively, and hence the total conservation costs of a farmer of type $i$ are $C_{i}(b)=F_{i}+c_{i}(b)$ if $b>0$. Both the fixed and variable costs are assumed to be beyond the control of each individual farmer; to supply a strictly positive amount of conservation services, he needs to incur fixed costs $F_{i}$ and variable costs $c_{i}(b) .{ }^{6}$ Here, $F_{i} \geq 0$, and $c_{i}\left(b_{i}\right)$ is assumed to be increasing and convex in $b_{i}$ with $c_{i}(0)=c_{i}^{\prime}(0)=0$. Also, without loss of generality, we assume that type 1 farmers are the ones with lowest marginal conservation

\footnotetext{
6 In other words, a farmer's type is defined by the fixed and variable conservation costs he incurs when providing conservation services, and not the other way around. Hence, a farmer cannot choose between cost structures $\left(F_{1}, c_{1}(b)\right)$ and $\left(F_{2}, c_{2}(b)\right)$; factors beyond his control (like the natural depth of the water table below his land-see the example in the Introduction) determine wich of the two cost structures he faces.
} 
costs: $c_{2}^{\prime}(b)>c_{1}^{\prime}(b)$ and $c_{2}^{\prime \prime}(b)>c_{1}^{\prime \prime}(b)$, for all $b>0 .{ }^{7}$ Finally, conservation services yield benefits equal to $E(B)$, where $B=\sum_{i=1}^{2} n_{i} b_{i}$ is the aggregate amount of conservation services provided, with $E^{\prime}(B)>0$ and $E^{\prime \prime}(B) \leq 0$.

We assume that the regulator aims to maximize the social net benefits of nature conservation consisting of conservation benefits $E(B)$, of the total amount of conservation costs incurred by the farmers $\left(C_{i}\left(b_{i}\right), i=1,2\right)$, and of the social costs of raising funds to compensate the farmers for the conservation services they provide. Regarding the latter, let $t>0$ be the social marginal cost of raising funds, which, for simplicity, is assumed to be constant and independent of the aggregate amount of compensation offered. Participation is voluntary, and hence farmers of type $i$ need to receive compensation payments (or subsidies, $S_{i}$ ) that are at least as large as the total amount of conservation costs they incur for the amount of services the contract prescribes them to supply $\left(S_{i} \geq C_{i}\left(b_{i}\right)\right){ }^{8}$

If the regulator has perfect information about each farmer, she can maximize the social net conservation benefits taking into account the participation constraints of the farmers of each type:

$$
\begin{array}{cl}
\max _{b_{1}, b_{2}, S_{1}, S_{2}} & E(B)-\sum_{i=1}^{2} n_{i}\left[c_{i}\left(b_{i}\right)+F_{i}\right]-t \sum_{i=1}^{2} n_{i} S_{i}, \\
\text { s.t. } & S_{i}-c_{i}\left(b_{i}\right)-F_{i} \geq 0, \quad i=1,2 .
\end{array}
$$

Typically, the regulator is less well-informed about farmers' individual characteristics than the farmers themselves. We assume that each farmer has perfect information about his own characteristics (that is, he knows $c_{i}(b)$ and $F_{i}$ ) while the regulator knows that there are $n_{i}$ farmers of type $i$ that face conservation cost structure $\left(c_{i}(b), F_{i}\right)$, but does not know the cost structure of each individual farmer she is confronted with. Hence, both the fixed and variable costs of individual farmers are assumed to be unobservable to the regulator. ${ }^{9}$ The information asymmetry implies that the regulator has to take into account the incentive compatibility constraints; the menu of contracts offered must be such that each farmer (weakly) prefers the particular contract designed for his type. Using $-i$ to denote the farmer type not equal to $i,{ }^{10}$ the regulator needs to ensure that $S_{i}-c_{i}\left(b_{i}\right)-F_{i} \geq S_{-i}-c_{i}\left(b_{-i}\right)-F_{i}$, or

\footnotetext{
7 Using the hydrological example presented in the Introduction, in arid regions a farmer with high groundwater tables will face high variable conservation costs because the net agricultural revenues foregone are large. In this paper's notation, this farmer would be a type 2 farmer, and a farmer facing a low water table would be a type 1 farmer-because we assume that $c_{2}^{\prime}(b)>c_{1}^{\prime}(b)$ for all $b>0$, so that $c_{2}(b)>c_{1}(b)$. Furthermore, in the example the fixed costs of providing conservation services would be relatively low for a farmer with high water tables (because he needs to dig less deep to create a pond), so that we would have $F_{2}<F_{1}$. Hence, in the hydrological example each farmer type's fixed and variable costs are negatively correlated-but there are also examples in which the relationship is positive (see also Sect. 5).

8 Our model is essentially static, as is typically the case in the adverse selection literature. Hence, the costs, benefits and subsidies should be viewed as net present values of the their per-period flows, discounted over the relevant time horizon. Also, we ignore any moral hazard issues here, as is typically the case in adverse selection models (but see Ozanne et al. 2001 and White 2002).

9 Because the depth of the water table is unobservable to the regulator, she cannot infer what level of fixed costs a farmer will incur when he starts to provide conservation services. Hence, she cannot just set a farmer's compensation payments equal to the sum of the actual fixed costs he incurs and of the variable conservation costs given the type he reports to be. If she were able to do that, only the variable conservation costs would matter for incentive-compatibility, and hence our model would be identical to those of Moxey et al. (1999) and of Wu and Babcock (1995).
}

10 That is, $-i=2(1)$ if $i=1(2)$. 


$$
S_{i}-c_{i}\left(b_{i}\right) \geq S_{-i}-c_{i}\left(b_{-i}\right),
$$

for $i=1,2 .^{11}$

We assume that the regulator wants the farmers of both types to implement conservation measures; it is socially optimal to induce all farmers of type 1 and 2 to offer conservation services even if the regulator is restricted to offering a uniform policy. ${ }^{12}$ A uniform policy consists of a single contract with a specific combination of $b$ and $S$ that is offered to all farmers. Such a uniform policy, $\left(S^{u}, b^{u}\right)$, is trivially incentive compatible and that means that one of the participation constraints will not be binding: one farmer type will receive more subsidies than strictly needed. But the regulator may also offer a menu of contracts consisting of specific combinations of $S$ and $b$ targeted at the different farmer types, i.e., $\left(S_{1}, b_{1}\right)$ and $\left(S_{2}, b_{2}\right)$, respectively. Key questions are whether such a separating scheme yields a higher level of social welfare than the best uniform policy, and whether the complete information solution is incentive compatible in the presence of information asymmetries. ${ }^{13}$

\section{Complete Information}

Let us first determine the complete information (or first-best) solution, i.e., the menu of subsidies and management requirements $\left\{\left(S_{1}, b_{1}\right),\left(S_{2}, b_{2}\right)\right\}$ that solves problem (1). The Lagrangian is the following:

$$
\begin{aligned}
L= & E\left(\sum_{i=1}^{2} n_{i} b_{i}\right)-\sum_{i=1}^{2} n_{i}\left[c_{i}\left(b_{i}\right)+F_{i}\right]-\sum_{i=1}^{2} t n_{i} S_{i} \\
& +\sum_{i=1}^{2} \lambda_{i}\left[S_{i}-c_{i}\left(b_{i}\right)-F_{i}\right],
\end{aligned}
$$

where $\lambda_{i} \geq 0$ is the Kuhn-Tucker multiplier associated with type $i^{\prime} s$ participation constraint $(i=1,2)$. The corresponding Kuhn-Tucker conditions are:

\footnotetext{
${ }^{11}$ In short, the timing of the game is as follows. Nature chooses each farmer's type as reflected by the fixed and variable conservation costs he faces, the regulator offers a menu of contracts, each farmer observes the menu and chooses the contact that maximizes his welfare.

12 More specifically, we assume that the optimal uniform policy yields positive net social benefits, and also that these benefits are larger than those obtained if farmers with higher total conservation costs were not induced to provide conservation services. This is the relevant case for our study. If not, it would be socially optimal to either just those farmers offer conservation services that can do so at least cost, or to have no farmers offer any services, and both cases can be trivially implemented even in the presence of information asymmetries.

13 Obviously, the model developed in this paper is simplified in several respects. First, we just focus on the case where the regulator tries to induce two farmer types to implement conservation measures - but the model can easily be extended to analyze the cases where there are many farmer types, and where the regulator wishes to induce two or more types to implement conservation. Second, we abstract from the moral hazard problem that is inherently present in real-world situations-that non-compliance with the required conservation levels is hard to detect (but see for example Ozanne et al. 2001 and White 2002). Third, we assume that the regulator has perfect information about the (economic) characteristics of the various farmer types but does not know which farmer is of what type. We therefore focus on an asymmetry in status information but not on asymmetries in the ability to collect information (cf. Goeschl and Lin 2003). Fourth, we assume that the regulator knows the distribution of types, but does not have any farmer-specific information on the basis of which she could assign prior beliefs regarding each farmer's actual type (but see Moxey et al. 1999). Fifth, our model is such that even under asymmetric information, the amount of conservation effort is always higher in case of a conservation scheme than in its absence because we assume that the privately optimal level of conservation effort is zero (but see Motte et al. 2004 and di Corato 2006).
} 


$$
\begin{aligned}
n_{i} E^{\prime}(B)-n_{i} c_{i}^{\prime}\left(b_{i}\right)-\lambda_{i} c_{i}^{\prime}\left(b_{i}\right) & =0, \\
\lambda_{i}-t n_{i} & =0, \\
\lambda_{i}\left[S_{i}-c_{i}\left(b_{i}\right)-F_{i}\right] & =0 ; \lambda_{i} \geq 0 ; S_{i}-c_{i}\left(b_{i}\right)-F_{i} \geq 0,
\end{aligned}
$$

for $i=1$, 2. Since $\lambda_{i}=t n_{i}>0$, the complete-information solution is such that:

$$
\begin{aligned}
S_{i}^{c} & =c_{i}\left(b_{i}^{c}\right)+F_{i}, \\
E^{\prime}\left(B^{c}\right) & =(1+t) c_{i}^{\prime}\left(b_{i}^{c}\right) \quad \text { for } i=1,2,
\end{aligned}
$$

where superscript $c$ refers to the complete information solution. Condition (3a) indicates that the subsidies paid should exactly cover the conservation costs so that the participation constraints are met with strict equality. And condition (3b) says that optimal conservation should be such that the social marginal benefits of conservation equal social marginal costs. The private marginal conservation costs are $c_{i}^{\prime}\left(b_{i}^{c}\right)$, but because raising funds for compensation payments is costly, social marginal costs are equal to $(1+t) c_{i}^{\prime}\left(b_{i}^{c}\right)$. That means that $E^{\prime}\left(B^{c}\right)>c_{i}^{\prime}\left(b_{i}^{c}\right)$ if $t>0$; the more severe the financial distortion (that is, the larger $t$ ), the lower the optimal aggregate conservation services provided $B^{c}$, and hence the larger the environmental distortion. Also, from condition (3b) we have that $b_{1}^{c}>b_{2}^{c}$ and $c_{1}\left(b_{1}^{c}\right)>c_{2}\left(b_{2}^{c}\right) .{ }^{14}$ Hence, the level of conservation services that should be provided by type 1 farmers is larger than that to be supplied by type 2 farmers, and the total variable conservation costs thus incurred by type 1 farmers are larger than those incurred by type 2 farmers. However, there is no unique ranking with respect to the required subsidy levels because of the presence of fixed costs. Clearly, $S_{1}^{c}=C_{1}^{c}>(<) C_{2}^{c}=S_{2}^{c}$ if and only if $F_{2}-F_{1}<(>) c_{1}\left(b_{1}^{c}\right)-c_{2}\left(b_{2}^{c}\right)$.

\section{Asymmetric Information}

We now consider the case in which each individual farmer knows his type (as defined by the fixed and variable cost functions he faces; $\left(F_{i}, c_{i}(b)\right)$, but the regulator only knows the characteristics of the two types $\left(F_{i}\right.$ and $\left.c_{i}\left(b_{i}\right), i=1,2\right)$ and the total number of farmers $\left(n_{1}\right.$ and $n_{2}$ ); she does not know which farmer is of what type. Hence, the regulator must take into account the incentive compatibility constraints given in (2), and the optimization problem she faces is the following:

$$
\begin{array}{rl}
\max _{b_{1}, S_{1}, b_{2}, S_{2}} & E(B)-\sum_{i=1}^{2} n_{i}\left[c_{i}\left(b_{i}\right)+F_{i}\right]-\sum_{i=1}^{2} t n_{i} S_{i}, \\
\text { s.t. } & S_{i}-c_{i}\left(b_{i}\right)-F_{i} \geq 0, i=1,2 \\
& S_{i}-c_{i}\left(b_{i}\right) \geq S_{-i}-c_{i}\left(b_{-i}\right), i=1,2 .
\end{array}
$$

In Sect. 4.1 we determine whether the least-cost solution under asymmetric information is separating, or uniform; in Sect. 4.2, we derive the optimal separating contract, as well as the circumstances under which the complete information solution is incentive compatible. ${ }^{15}$

\footnotetext{
$\overline{14}$ Condition (3b) implies $c_{1}^{\prime}\left(b_{1}^{c}\right)=c_{2}^{\prime}\left(b_{2}^{c}\right)$, and because $c_{1}^{\prime}(b)<c_{2}^{\prime}(b) \forall b>0$, we have $b_{1}^{c}>b_{2}^{c}$. Totally differentiating $c_{1}^{\prime}\left(b_{1}^{c}\right)=c_{2}^{\prime}\left(b_{2}^{c}\right)$ yields $d b_{1}^{c} / d b_{2}^{c}=c_{2}^{\prime \prime} / c_{1}^{\prime \prime}>1$. Now for any level of $b_{2}^{c}>0$ (with corresponding $\left.b_{1}^{c}\right)$, we have $d\left(c_{1}\left(b_{1}^{c}\left(b_{2}^{c}\right)\right)-c_{2}\left(b_{2}^{c}\right)\right) / d b_{2}^{c}=c_{1}^{\prime}\left(b_{1}^{c}\right) d b_{1}^{c} / d b_{2}^{c}-c_{2}^{\prime}\left(b_{2}^{c}\right)=\left(E^{\prime} /(1+t)\right)\left[d b_{1}^{c} / d b_{2}^{c}-1\right]>$ 0 , and straightforward integration yields $c_{1}\left(b_{1}^{c}\right)-c_{2}\left(b_{2}^{c}\right)>0$.

15 Note that we assume that it is socially optimal if both types offer conservation services. Our model can easily be generalized to the case of $N \geqslant 2$ farmer types, where the regulator wishes to induce $K \leq N$ types to provide conservation services. $K \geqslant 2$ implies that there are potential gains from separating the $K$ types.
} 


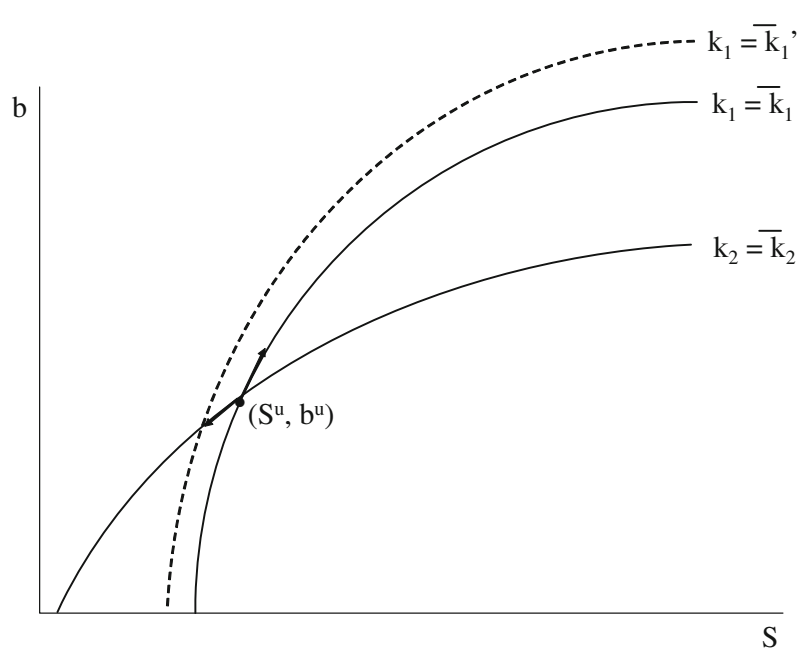

Fig. 1 A subsidy-saving deviation from the least-cost uniform policy

\subsection{Uniform Versus Separating Policies}

We first determine whether the optimal policy under asymmetric information is uniform (i.e., consisting of one combination of $S$ and $b$ offered to all farmers), or whether offering a menu of contracts can be socially preferred. The formal analysis is provided in Appendix A; for ease of interpretation, we present a graphical analysis in this subsection.

To evaluate whether menus of contracts are incentive compatible, we use isocost curves to evaluate farmer preferences regarding the various service provision levels/compensation payments available. An isocost curve represents the set of policy combinations $(S, b)$ such that total (net) costs for type $i$ farmers are constant: $k_{i}=F_{i}+c_{i}(b)-S$. Since $\left.\frac{d b}{d S}\right|_{k_{i}}=\frac{1}{c_{i}^{\prime}(b)}$, isocost curves are upward-sloping and concave in $(S, b)$ space; see Fig. 1. When receiving an extra dollar of subsidies, type $i$ farmers are willing to supply more conservation services, but at a decreasing rate- because the costs of providing conservation services are convex. Also, net costs decrease whenever the required services level is lower and the subsidy is larger. Hence, for a given $k_{i}(S, b)=\bar{k}_{i}$, all policy combinations located to the south-east (north-west) of this isocost curve result in lower (higher) net costs for farmers of type $i$, and hence these farmers prefer policy combinations on isocost curves located to the south-east to those on isocost curves located to the north-west (as is illustrated in Fig. 1 for type 1 farmers, where $\left.\bar{k}_{1}^{\prime}>\bar{k}_{1}\right)$. Finally, because $\left.\frac{d b}{d S}\right|_{k_{i}}=\frac{1}{c_{i}^{\prime}(b)}$ and because $c_{2}^{\prime}(b)>c_{1}^{\prime}(b)$, the isocost curve of a type 1 farmer is strictly steeper in any policy combination $(S, b)$ than that of a type 2 farmer, that is, $\left.\frac{d b}{d S}\right|_{k_{1}}>\left.\frac{d b}{d S}\right|_{k_{2}}$.

Figure 1 allows us to show the intuition behind the result that the optimal policy is never a uniform policy. Consider the uniform policy $\left(S^{u}, b^{u}\right)$ and the two isocost curves $k_{1}(S, b)=\bar{k}_{1}$ and $k_{2}(S, b)=\bar{k}_{2}$ that run through this policy combination. ${ }^{16}$ We prove that this is never the

Footnote 15 continued

The same analytical tools developed for analyzing the case $N=K=2$ can be used to analyze $N \geqslant K \geqslant 2$, independent of whether it is socially optimal to have all farmer types offer conservation services $(N=K>2)$ or only a subset of them $(N>K \geqslant 2)$.

16 Here, $\bar{k}_{i}=F_{i}+c_{i}\left(b^{u}\right)-S^{u}, i=1,2$. 
optimal policy because there always exists a menu of policy combinations that can achieve the same aggregate level of conservation $B^{u}=\left(n_{1}+n_{2}\right) b^{u}$ while spending less money on subsidies. We do this by showing that the aggregate amount of subsidies offered falls if the regulator sets the policy combination targeted at type 1 farmers on the $k_{1}(S, b)=\bar{k}_{1}$ curve to the north-east of $\left(S^{u}, b^{u}\right)$, and the combination targeted at type 2 farmers on the $k_{2}(S, b)=\bar{k}_{2}$ curve to the south-west of $\left(S^{u}, b^{u}\right)$. Such a set of combinations is both incentive compatible and decreases the total amount of subsidies paid.

The analysis is as follows. First note that decreasing $b_{2}$ implies increasing $b_{1}$ as the aggregate conservation level $B^{u}$ should remain unchanged. Totally differentiating $B^{u}=$ $n_{1} b_{1}+n_{2} b_{2}$ yields $d b_{2} / d b_{1}=-\left(n_{1} / n_{2}\right)$. Next, we can infer the required change in subsidies $\left(d S_{i}\right)$ for the amount of the change in conservation services imposed $\left(d b_{i}\right)$; this equals $\partial S_{i}\left(b^{u}\right) / \partial b=c_{i}^{\prime}\left(b^{u}\right)$. The aggregate amount of subsidies required $(\tilde{S})$ varies with $b_{1}$ as follows: $d \tilde{S} / d b_{1}=n_{1} \frac{\partial S_{1}\left(b^{u}\right)}{\partial b_{1}}+n_{2} \frac{\partial S_{2}\left(b^{u}\right)}{\partial b_{2}} \frac{d b_{2}}{d b_{1}}=-n_{1}\left(c_{2}^{\prime}\left(b^{u}\right)-c_{1}^{\prime}\left(b^{u}\right)\right)<0$ because $c_{2}^{\prime}(b)>$ $c_{1}^{\prime}(b)$ for all $b>0$. Therefore, starting from $\left(S^{u}, b^{u}\right)$, marginally increasing $b_{1}$ (and concomitantly decreasing $b_{2}$ ) reduces the total amount of subsidies paid. Finally, when moving along the two $k_{i}(S, b)=\bar{k}_{i}$ curves (to the north-east for type 1 and to the south-west for type 2), each farmer strictly prefers the new policy combination targeted at his type.

Hence, in line with the standard result of the literature on asymmetric information (see for example Smith 1995; Smith and Tomasi 1995; Wu and Babcock 1995, 1996, and Moxey et al. 1999), the uniform policy is never optimal; independent of the number of farmers being of type 1 or type $2\left(n_{1}, n_{2}>0\right)$, it is always cheaper to induce the low-cost (high-cost) farmers to supply slightly more (less) conservation services. Also note that incentive compatible policies are then characterized by higher (lower) service provision levels and subsidies intended for the low (high) variable cost type-independent of the level of the fixed costs.

\subsection{The Optimal Policy Under Asymmetric Information}

Let us now address the question whether the complete information (or first-best) solution can be incentive compatible in the presence of fixed costs. The first-best policy is incentive compatible if and only if the participation constraints in problem (4) hold with equality for $i=1,2$, and both incentive compatibility constraints are (weakly) met. Combining these four equations, we find that the first-best solution is incentive compatible if and only if

$$
c_{2}\left(b_{2}^{c}\right)-c_{1}\left(b_{2}^{c}\right) \leq F_{1}-F_{2} \leq c_{2}\left(b_{1}^{c}\right)-c_{1}\left(b_{1}^{c}\right) .
$$

Because $c_{2}^{\prime}(b)>c_{1}^{\prime}(b)$ for all $b>0$ and because $b_{1}^{c}>b_{2}^{c}$, we have (i) $0 \leq c_{2}\left(b_{2}^{c}\right)-$ $c_{1}\left(b_{2}^{c}\right)$, and (ii) $c_{2}\left(b_{2}^{c}\right)-c_{1}\left(b_{2}^{c}\right)<c_{2}\left(b_{1}^{c}\right)-c_{1}\left(b_{1}^{c}\right)$. Here, (i) indicates that the first-best solution is never incentive compatible if $F_{1} \leq F_{2}$ (which includes the possibility of $F_{1}=F_{2}=0$ as typically assumed by the extant literature on green payments), but (ii) implies that the first-best solution can be incentive compatible for at least some combinations of fixed costs as long as $F_{1}>F_{2} \geq 0$. Hence, a necessary (but not a sufficient) condition for the first-best policy to be incentive compatible is that the farmers with the lowest variable costs should face larger fixed costs than the other type $\left(F_{1}>F_{2}\right)$. If the low variable cost type faces smaller fixed costs or if there are no fixed costs associated with conservation at all, the low variable cost type can always provide the conservation level targeted at the high cost type at lower costs and hence make a profit. ${ }^{17}$

17 Although the specific levels $\left(b_{1}^{c}, b_{2}^{c}\right)$ are contingent on the regulator aiming to maximize social net benefits (1), condition (5) holds independently of the regulator's objective; it also applies if the principal aims to 


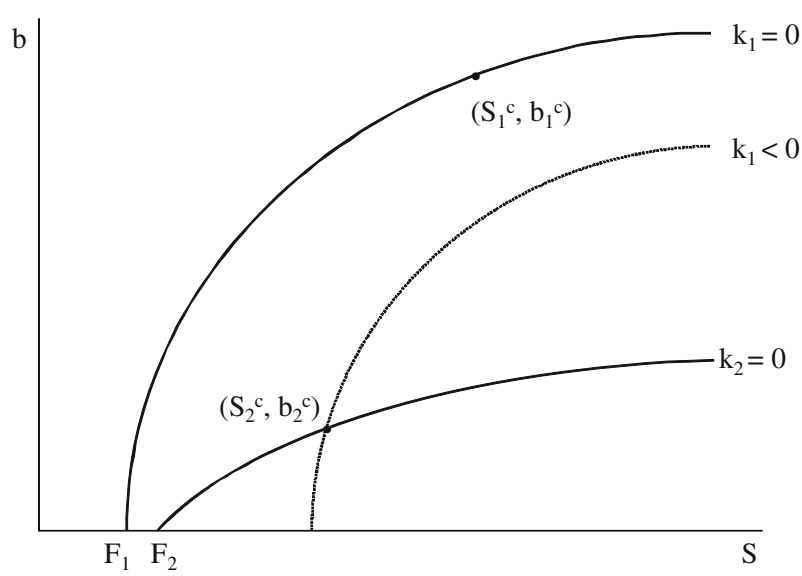

Fig. 2 Incentive compatibility of the first-best policy $\left\{\left(S_{1}^{c}, b_{1}^{c}\right),\left(S_{2}^{c}, b_{2}^{c}\right)\right\}$ if $F_{2} \geq F_{1} \geq 0$

One might expect fixed costs to be irrelevant for the optimization problem because they need to be incurred as soon as farmers decide to provide positive levels of conservation, independent of the contract chosen. On the contrary, we find that fixed costs play a crucial role because the first-best solution is incentive compatible for some levels and combinations of fixed costs, but not for others. The reason why the two fixed costs appear in the incentive compatibility constraint is that their levels affect the amount of subsidies provided. This result is clear when analyzing the two inequalities in (5) separately.

The first inequality in (5) can be rewritten as $c_{2}\left(b_{2}^{c}\right)+F_{2} \leq F_{1}+c_{1}\left(b_{2}^{c}\right)$, and subsequently as $0 \leq F_{1}+c_{1}\left(b_{2}^{c}\right)-S_{2}^{c}$. In words, this inequality is about the incentives for type 1 farmers to misrepresent their type under the first-best solution. Their net costs are zero if they choose the policy combination aimed at their type, and this is incentive compatible if they incur non-negative conservation costs if they misrepresent themselves. So, even though $c_{1}\left(b_{2}^{c}\right)<c_{1}\left(b_{1}^{c}\right)$, type 1 farmers may still prefer the policy targeted at their type if $S_{2}^{c}$ is sufficiently small compared to $S_{1}^{c}$, and this is the case if $F_{2}$ is sufficiently small compared to $F_{1}$. And a similar analysis applies to the second inequality of (5), which can be rewritten as $c_{1}\left(b_{1}^{c}\right)+F_{1} \leq c_{2}\left(b_{1}^{c}\right)+F_{2}$ and hence as $0 \leq F_{2}+c_{2}\left(b_{1}^{c}\right)-S_{1}^{c}$. Type 2 farmers have an incentive to choose the combination aimed at their type because $c_{2}\left(b_{2}^{c}\right)<c_{2}\left(b_{1}^{c}\right)$, but they will only actually do so if $S_{1}^{c}\left(S_{2}^{c}\right)$ is sufficiently low (high), which is the case if $F_{1}\left(F_{2}\right)$ is sufficiently small (large).

This can also be shown graphically. Let us first consider the case where $F_{1} \leq F_{2}$ so that we have $C_{1}(b)<C_{2}(b)$ for all $b>0$, which is depicted in Fig. 2. In this case the first-best solution is not incentive compatible, according to condition (5). For $b$ infinitesimally close to zero, the minimum amount of subsidies required to induce type $i$ farmers to invest in conservation is equal to $S_{i}=F_{i}$, and $F_{1} \leq F_{2}$ implies that the horizontal intercept of the zero-cost isocost curve of type 1 farmers, $k_{1}(S, b)=0$, is (weakly) to the left of the zero-cost isocost curve of type 2 farmers, $k_{2}(S, b)=0$. Next, because $\left.\frac{d b}{d S}\right|_{k_{1}}=\frac{1}{c_{1}^{\prime}(b)}>\frac{1}{c_{2}^{\prime}(b)}=\left.\frac{d b}{d S}\right|_{k_{2}}$ for all $b>0, k_{1}(S, b)=0$ is located strictly to the north of $k_{2}(S, b)=0$. Hence, if $F_{1} \leq F_{2}$,

Footnote 17 continued

maximize conservation benefits achieved for a given budget, or if she aims to achieve a specific conservation level at minimum cost, see footnote 5. The reason is that condition (5) is based exclusively on the participation and incentive-compatibility constraints and not on the regulator's objective function. 
type 1 farmers always prefer the first-best policy contract offered to type 2 farmers to the first-best contract intended for themselves. ${ }^{18}$

So we have that if $F_{1} \leq F_{2}$, the first-best solution is never incentive compatible, and hence we need to derive the second-best policy for this case. From Sect. 4.1 we know that this second-best policy is always separating. Indeed, in this case the optimal policy is characterized as follows (for a formal proof see Appendix B):

$$
\begin{aligned}
& (1+t) c_{1}^{\prime}\left(b_{1}^{s}\right)=E^{\prime}\left(B^{s}\right) \\
& (1+t) c_{2}^{\prime}\left(b_{2}^{s}\right)=E^{\prime}\left(B^{s}\right)-\frac{n_{1}}{n_{2}} t\left[c_{2}^{\prime}\left(b_{2}^{s}\right)-c_{1}^{\prime}\left(b_{2}^{s}\right)\right] \\
& S_{1}^{s}-c_{1}\left(b_{1}^{s}\right)-F_{1}=S_{2}^{s}-c_{1}\left(b_{2}^{s}\right)-F_{1} \\
& S_{2}^{s}-c_{2}\left(b_{2}^{s}\right)-F_{2}=0,
\end{aligned}
$$

where superscript $s$ indicates that the policy is second-best. Equation 6a is the "no distortion at the top" condition (cf. Macho-Stadler and Pérez-Castrillo 2001). It says that the amount of services provided by type 1 farmers should be such that the social marginal costs of conservation equal the social marginal benefits. Since $c_{2}^{\prime}(b)-c_{1}^{\prime}(b)>0$, Eq. $6 \mathrm{~b}$ states that $E^{\prime}\left(B^{s}\right)>(1+t) c_{2}^{\prime}\left(b_{2}^{s}\right)$; the amount of services that should be provided by type 2 farmers is smaller than the level that would equate the marginal social conservation costs to the social marginal benefits of conservation. ${ }^{19}$ Because we consider the case where $\left(S_{2}^{c}=\right) c_{2}\left(b_{2}^{c}\right)+F_{2}>c_{1}\left(b_{2}^{c}\right)+F_{1}$ and because (3b) implies that $b_{1}^{c}>b_{2}^{c}$, type 1 farmers have an incentive to misrepresent their type when confronted with the complete information contracts, but type 2 farmers do not. Hence, condition (6c) indicates that type 1 farmers should be indifferent between the two contracts, while condition (6d) implies that type 2 farmers receive compensation that is exactly equal to the conservation costs incurred. Next, substituting (6d) into (6c), we have $S_{1}^{s}-c_{1}\left(b_{1}^{s}\right)-F_{1}=c_{2}\left(b_{2}^{s}\right)+F_{2}-c_{1}\left(b_{2}^{s}\right)-F_{1}>0$ (cf. 5); type 1 farmers receive excess compensation (or an informational rent) for the conservation services they provide. So we derive that $b_{2}^{s}<b_{2}^{c}$ and $S_{1}^{s}>c_{1}\left(b_{1}^{s}\right)-F_{1}$, and this is the double cost of incentive-compatible contracts alluded to in the introduction. Type 2 farmers are just compensated for the conservation services they provide but the actual amount supplied is less than the amount of services that would equate the marginal social conservation costs to the social marginal benefits $\left(E^{\prime}\left(B^{s}\right)>(1+t) c_{2}^{\prime}\left(b_{2}^{s}\right)\right)$, while type 1 farmers offer the socially optimal amount of services but at the cost of receiving informational rents equal to $R_{1} \equiv S_{1}-F_{1}-c_{1}\left(b_{1}\right)>0$ (implying a social cost of $\left.t R_{1}>0\right){ }^{20}$

We have thus shown that $F_{1}>F_{2} \geq 0$ is a necessary condition for the first-best solution to be incentive compatible, but condition (5) indicates that it is not a sufficient one. If $F_{1}>F_{2} \geq 0$, the zero-cost isocost curves of the two types, $k_{1}(S, b)=0$ and $k_{2}(S, b)=0$,

\footnotetext{
18 Recall that the extant literature on payments for ecosystem services assumes that all conservation costs vary with the amount of services provided, and that it concludes that the first-best solution is never incentive compatible (see for example Smith 1995; Smith and Tomasi 1995; Moxey et al. 1999; Wu and Babcock 1995, 1996, and Ferraro 2008). We replicate this result because $F_{1} \leq F_{2}$ encompasses the case where $F_{1}=F_{2}=0$-the first best is never incentive compatible if all conservation costs vary with the amount of services provided.

${ }^{19}$ Even though (6a) equates marginal social benefits and costs, we still have $b_{1}^{s} \neq b_{1}^{c}$. This is because (6b) implies that $b_{2}^{s}<b_{2}^{c}$ so that $E^{\prime}\left(B^{s}\right)>E^{\prime}\left(B^{c}\right)$. That means that (6a) implies that $b_{1}^{s}>b_{1}^{c}$.

${ }^{20}$ Indeed, the conservation distortion $b_{2}^{s}<b_{2}^{c}$ reduces the excess compensation received by type 1 farmers. From condition (6c), $R_{1}=S_{1}-F_{1}-c_{1}\left(b_{1}\right)=c_{2}\left(b_{2}\right)-c_{1}\left(b_{2}\right)+F_{2}-F_{1}$ and hence $d R_{1} / d b_{2}=c_{2}^{\prime}\left(b_{2}\right)-$ $c_{1}^{\prime}\left(b_{2}\right)>0$. By decreasing $b_{2}$, the social costs of the informational rents are reduced by $n_{1} t\left[c_{2}^{\prime}\left(b_{2}\right)-c_{1}^{\prime}\left(b_{2}\right)\right]$ at the costs of an environmental distortion for each of the $n_{2}$ farmers of magnitude $E^{\prime}\left(B^{s}\right)-(1+t) c_{2}^{\prime}\left(b_{2}^{s}\right)>0$. Optimality requires balancing these marginal benefits and costs of adjusting $b_{2}$, which yields (6b).
} 


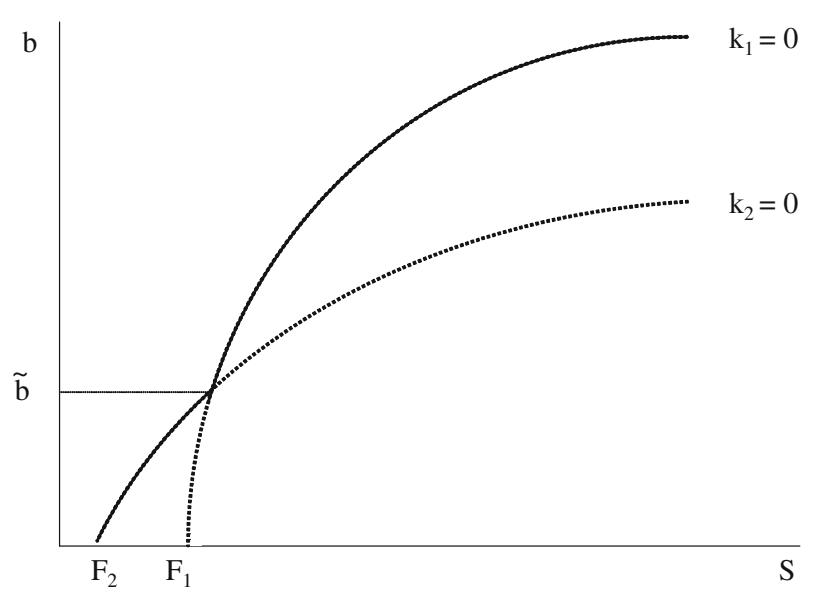

Fig. 3 Incentive compatibility of the first-best policy if $F_{1}>F_{2} \geq 0$

intersect at one particular level of $b$, labelled $\tilde{b}$ in Fig. 3. We know from the previous subsection that the optimal solution is always a separating policy, and we show that in this case the first-best separating policy may even be incentive compatible. Here, the outcome depends on the relative values of the fixed and variable costs incurred.

Suppose that the first-best solution is such that either $b_{2}^{c}<b_{1}^{c}<\tilde{b}$, or $\tilde{b}<b_{2}^{c}<b_{1}^{c}$. That means that in either case, one of the two policy combination is located on the dotted part of either of the two isocost curves in Fig. 3, and the first-best policy is not incentive compatible. If $\tilde{b}<b_{2}^{c}<b_{1}^{c}$, the situation is analogous to the one depicted in Fig. 2 and hence type 1 farmers strictly prefer the contract intended for type 2 farmers. In fact, condition $\tilde{b}<b_{2}^{c}<b_{1}^{c}$ is equivalent to $F_{1}-F_{2}<c_{2}\left(b_{2}^{c}\right)-c_{1}\left(b_{2}^{c}\right)$, which violates (5). In that case, the optimal separating policy is again (6a)-(6d), that is, an informational rent must be given to type 1 farmers.

Alternatively, we may have $b_{2}^{c}<b_{1}^{c}<\tilde{b}$, and in this case type 2 farmers strictly prefer the contract intended for type 1 farmers. Here, condition $b_{2}^{c}<b_{1}^{c}<\tilde{b}$ is equivalent to $F_{1}-F_{2}>c_{2}\left(b_{1}^{c}\right)-c_{1}\left(b_{1}^{c}\right)$, which violates (5). In this case it is the type 2 farmers who have an incentive to misrepresent themselves (as $S_{1}^{c}=F_{1}+c_{1}\left(b_{1}^{c}\right)>c_{2}\left(b_{1}^{c}\right)+F_{2}$ ) rather than type 1 farmers. The second-best policy is then again a separating contract which is identical to (6a)-(6d) except that all subscripts "1" should now read "2", and vice versa.

If, however, $b_{2}^{c} \leq \tilde{b} \leq b_{1}^{c}$ (with at least one of the two inequalities being strict), the first-best solution is incentive compatible, since condition (5) holds. For type 2 farmers the difference in subsidies $\left(S_{1}^{c}-S_{2}^{c}\right)$ is always smaller than the increase in variable costs they incur when representing themselves as type 1 farmers; for type 1 farmers the difference in subsidies is always larger than the variable cost savings they obtain because of having to meet less strict management requirements $\left(b_{2}^{c}\right.$ versus $\left.b_{1}^{c}\right)$. We conclude that the first-best solution may be incentive compatible in the presence of information asymmetries if the fixed and variable conservation costs a farmer faces, are negatively correlated.

\section{Empirical Relevance}

We find that the complete-information (or first-best) solution may be incentive compatible if and only if the fixed and variable conservation costs are negatively correlated. In principle, 
Table 1 Examples of external factors giving rise to systematic relationships between fixed and variable conservation costs

\begin{tabular}{lll}
\hline Unobserved factor $z$ & Impact on $\partial c(b, z) / \partial b$ & Impact on $F(z)$ \\
\hline Hydrology: depth of water table & & \\
$\quad$ Arid regions & $\partial^{2} c / \partial b \partial z<0$ & $\partial F / \partial z>0$ \\
$\quad$ Water-abundant regions & $\partial^{2} c / \partial b \partial z>0$ & $\partial F / \partial z>0$ \\
Infrastructure: distance to (paved) roads & & \\
Generic plant and animal diversity & $\partial^{2} c / \partial b \partial z<0$ & $\partial F / \partial z>0$ \\
$\quad$ Conservation of charismatic species & $\partial^{2} c / \partial b \partial z<0$ & $\partial F / \partial z<0$ \\
Nature: distance to geese migration routes & & $\partial F / \partial z>0$ \\
$\quad$ Geese conservation & $\partial^{2} c / \partial b \partial z>0$ & $\partial F / \partial z<0$ \\
Conservation of species other than geese & $\partial^{2} c / \partial b \partial z>0$ & \\
\hline
\end{tabular}

there are many reasons why some farmers may face larger fixed setup costs and lower variable conservation costs - if only because there are so many cost categories in either cost type; cf. Naidoo et al. (2006). Indeed, as stated in that study (on p. 682), "[a] high cost of one type might not necessarily mean other cost types are high [too]." However, a systematic relationship between the fixed and variable costs is most likely to exist if the levels of both cost components are determined by the same underlying factor $z: c=c(b, z)$ and $F=F(z){ }^{21}$ With this idea in mind we surveyed the empirical literature on conservation programs, and found that there are indeed quite a few examples that meet the conditions required for this paper to be of practical relevance. We found examples of hydrological, natural and infrastructural factors (exogenous to the farmer) that are not easily observable by the regulator (or only at very high cost), and that cause farmers' fixed and variable conservation costs to be correlated (positively or negatively). These examples are summarized in Table 1.

In the introductory section to this paper we already presented the example of hydrological circumstances affecting the fixed and variable costs of providing conservation services in arid regions. In the above notation, if $z$ is measured as the distance between the earth's surface and the groundwater table, we find that the two cost components are negatively correlated (see Table 1). Both agricultural output and biodiversity are inversely related to $z$. The smaller $z$, the larger the opportunity costs of conservation, but the lower the set-up costs that need to be incurred for nature and wildlife to establish itself (in the form of creating, for example, watering holes; Garrido et al. 2006). Note that groundwater levels are largely unobservable to the regulator, and also a farmer's average agricultural yield may be a poor indicator of the water abundance underneath the hectares he puts up for conservation as groundwater depth tends to vary quite substantially over space (Mew et al. 1997). And even if different government bodies have a substantial amount of information about a farmer's agricultural productivity (in the form of his tax declarations) or the amount of energy he uses to pump up water for irrigation, coordination between the various government organizations is oftentimes lacking-also because merging data sets is not costless (see Llamas and Martínez-Santos 2005 and Martínez-Santos and Martínez-Alfaro 2010 for the case of Spain).

21 Using this notation, we can write up the model presented in Sect. 2 as follows: $z_{i}=\left\{z_{1}, z_{2}\right\}, z_{2}>$ $z_{1}, \partial^{2} c(b, z) / \partial b \partial z>0$ and $\partial F(z) / \partial z<>0$. This implies that $c_{1}^{\prime}(b) \equiv \partial c\left(b, z_{1}\right) / \partial b<\partial c\left(b, z_{2}\right) / \partial b \equiv$ $c_{2}^{\prime}(b)$ for all $b>0$, while $F_{2}=F\left(z_{2}\right)$ may or may not be larger than $F_{1}=F\left(z_{1}\right)$. 
So, in arid regions hydrological circumstances can cause the fixed and variable conservation costs to be negatively correlated, and hence the theory presented in Sect. 4.2 suggests that the first-best solution may be incentive compatible in this case. However, hydrological circumstances do not always result in a negative relationship between fixed and variable costs: in water-abundant countries, two cost components are likely to be positively correlated. For example, $40 \%$ of the local plants species in the Netherlands are threatened by (artificially) low water tables - agricultural crops require less water-saturated soils than nature (Boogerd et al. 1997). On farm land with low natural water tables (i.e., with high values of $z$ ), the variable opportunity costs of offering conservation services are high (because of the naturally high agricultural yields) while the cost of creating habitat are likely to be relatively high too. Raising the ground water table to create habitat for nature requires creating dams to prevent run-off (Boogerd et al. 1997) or planting vegetation that better retains water in the higher soil layers (Jansen et al. 2000). The fixed and variable costs are thus positively correlated in water-abundant regions, and hence in these cases the first-best solution is never incentive compatible.

Exogenous factors other than hydrological circumstances can affect a farmer's fixed and variable costs too. One example is the distance to infrastructures like roads; see Naidoo et al. (2006). Proximity to paved roads implies higher opportunity costs of conservation because easy access results in higher farm-gate prices. But if conservation requires (mechanized) construction of conservation structures like ponds or dams, proximity to road infrastructures implies lower transportation costs of bringing in the necessary equipment, and hence the fixed setup costs of offering conservation services are lower too. So, if $z$ is measured in terms of the distance to (paved) roads, the variable conservation costs are decreasing in $z$ while the fixed costs increase with this variable. Alternatively, if the objective is to conserve species that are sensitive to human disturbance (in the form of, for example, noise or intrusion) such as deer or wild boar, creating suitable habitat for populations to be built up is easier the larger the distance to (paved) road networks - if only because a larger distance to paved roads implies that fewer measures need to be undertaken to prevent automobile-wildlife collisions such as visual deterrents and/or physical barriers (Feldhammer et al. 1986; Romin and Bissonette 1996); see also Fritz et al. (2003) and Papouchis et al. (2001).

Similarly, nature itself may also influence the fixed and variable conservation costs a farmer faces. An example thereof is the migration patterns of birds, and especially geese. Geese can be a conservation target, but they can also be a threat to biodiversity because they may compete with other species for base resources and/or because they can be a vector of disease transmission; see Post et al. (1998). Proximity of a farmer's land to migration routes of geese implies that opportunity costs of conservation are low because preventing geese from ruining one's harvest is quite expensive. Hence, using $z$ to measure distance from migration routes, the smaller $z$, the smaller the opportunity costs of offering conservation services. Whether the fixed costs of constructing nature are high or low depends on the conservation objective. If the objective is to rebuild geese populations, proximity to migration routes implies that less investments need to be made to attract geese; if the objective is to protect other species, proximity to migration routes implies larger investments to prevent geese from competing for food with the conservation program's target species.

Hydrological circumstances, bird migration routes and infrastructural patterns are examples of factors affecting farmers' costs of providing conservation services, which are largely beyond the control of farmers themselves. Also, while these factors may be observable to the regulator in principle (as she can dispatch monitoring agents to verify the location of the land offered for conservation), the costs of doing so may be prohibitively high. 
The overview presented in Table 1 provides an important insight. If a particular set of circumstances is conducive to both agricultural yields and to nature conservation, the fixed and variable costs are likely to be negatively correlated; if one set of circumstances favors the one but not the other, they are positively correlated. If both nature and agriculture benefit from relatively abundant water supplies (as is the case in Spain), achieving conservation objectives is cheaper on land with high water tables but the opportunity costs in terms of agricultural revenue foregone are larger. If proximity of road networks facilitates creating the conditions for biodiversity conservation (for example if artificial ponds need to be dug), the costs of doing so are lower, but the opportunity costs are larger because easy access implies higher farm-gate prices. If both biodiversity conservation and agriculture suffer from foraging behavior of migratory birds like geese (because of competition for food resources, or because of the transmission of diseases), proximity to their migration routes implies that the opportunity cost of conservation are lower (as the net agricultural yields are lower-because birds feed on the crops, or because the farmer needs to spend resources on preventing foraging), but the costs of creating suitable habitat for other species are higher. If a particular set of circumstances favors nature but not agriculture or vice versa, our theory says that the first-best solution is never incentive compatible, but it may be if the same set of circumstances is conducive to both nature and cultivation.

\section{Conclusions}

Over the past two decades, a sizable literature has emerged on incentive-compatible contracts as a tool to induce conservation (e.g., Smith 1995; Smith and Tomasi 1995; Moxey et al. 1999; Wu and Babcock 1995, 1996; Ferraro 2008). This literature assumes that all conservation costs are variable in nature, and concludes that the complete-information (or first-best) solution is never incentive-compatible as farmers of the low-variable cost type have strong incentives to misrepresent themselves as high-variable cost farmers. We develop a model of asymmetric information that is very similar to the ones cited above, but differs from them because it takes into consideration that offering conservation services may require fixed set-up costs too.

While adding fixed cost to the existing models is a minor change in itself, the policy implications can be quite substantial because we find that the complete-information solution may be incentive compatible in the presence of information asymmetries. If all conservation costs are variable in nature, the optimal menu of contracts is always second-best. This is not necessarily the case when conservation entails fixed costs too. The first-best solution may be implementable under asymmetric information if farmers with lower variable conservation costs face higher fixed costs, and this is likely to be the case if the same set of circumstances is conducive to both nature and cultivation.

Our theory indicates that the first-best solution is never incentive-compatible in case unobserved factors benefit nature but not agriculture, or vice versa. In this case, the optimal menu of contracts is second-best, implying that less conservation is achieved than in the first-best, and also that the low-cost (fixed and variable) farmers receive informational rents. Given these two inefficiencies, it may not be worthwhile to the regulator to collect all the necessary information, and other instruments (like conservation auctions) may be preferred. However, if unobservable factors are conducive to both nature and agriculture, the first-best may be implementable under information asymmetries. In that case, the welfare gains from offering a menu of incentive-compatible conservation contracts may be substantial, and hence it may 
pay off for the regulator to invest in collecting all necessary information to design the optimal menu of contracts.

Open Access This article is distributed under the terms of the Creative Commons Attribution Noncommercial License which permits any noncommercial use, distribution, and reproduction in any medium, provided the original author(s) and source are credited.

\section{Appendix A}

The Lagrangian of problem (4) is the following:

$$
\begin{aligned}
L= & E(B)-\sum_{i=1}^{2} n_{i}\left[c_{i}\left(b_{i}\right)+F_{i}\right]-\sum_{i=1}^{2} t n_{i} S_{i} \\
& +\sum_{i=1}^{2} \lambda_{i}\left[S_{i}-c_{i}\left(b_{i}\right)-F_{i}\right]+\sum_{i=1}^{2} \gamma_{i}\left[S_{i}-c_{i}\left(b_{i}\right)-S_{-i}+c_{i}\left(b_{-i}\right)\right],
\end{aligned}
$$

and the corresponding Kuhn-Tucker conditions are:

$$
\begin{aligned}
& n_{1} E^{\prime}(B)-n_{1} c_{1}^{\prime}\left(b_{1}\right)-\lambda_{1} c_{1}^{\prime}\left(b_{1}\right)-\gamma_{1} c_{1}^{\prime}\left(b_{1}\right)+\gamma_{2} c_{2}^{\prime}\left(b_{1}\right)=0 \\
& n_{2} E^{\prime}(B)-n_{2} c_{2}^{\prime}\left(b_{2}\right)-\lambda_{2} c_{2}^{\prime}\left(b_{2}\right)+\gamma_{1} c_{1}^{\prime}\left(b_{2}\right)-\gamma_{2} c_{2}^{\prime}\left(b_{2}\right)=0 \\
& \lambda_{1}+\gamma_{1}-\gamma_{2}-t n_{1}=0 \\
& \lambda_{2}-\gamma_{1}+\gamma_{2}-t n_{2}=0 \\
& \lambda_{1}\left[S_{1}-c_{1}\left(b_{1}\right)-F_{1}\right]=0 ; \quad \lambda_{1} \geq 0 ; \quad S_{1}-c_{1}\left(b_{1}\right)-F_{1} \geq 0 \\
& \lambda_{2}\left[S_{2}-c_{2}\left(b_{2}\right)-F_{2}\right]=0 ; \quad \lambda_{2} \geq 0 ; \quad S_{2}-c_{2}\left(b_{2}\right)-F_{2} \geq 0 \\
& \gamma_{1}\left[S_{1}-c_{1}\left(b_{1}\right)-S_{2}+c_{1}\left(b_{2}\right)\right]=0 ; \quad \gamma_{1} \geq 0 ; S_{1}-c_{1}\left(b_{1}\right)-S_{2}+c_{1}\left(b_{2}\right) \geq 0 \\
& \gamma_{2}\left[S_{2}-c_{2}\left(b_{2}\right)-S_{1}+c_{2}\left(b_{1}\right)\right]=0 ; \quad \gamma_{2} \geq 0 ; \quad S_{2}-c_{2}\left(b_{2}\right)-S_{1}+c_{2}\left(b_{1}\right) \geq 0
\end{aligned}
$$

The uniform policy $\left(b^{u}, S^{u}\right)$ corresponds to the case where $\gamma_{1}>0, \gamma_{2}>0$ as $S_{i}-c_{i}\left(b_{i}\right)-$ $S_{-i}+c_{i}\left(b_{-i}\right)=0$ hold for $i=1,2$; see ( $7 \mathrm{~g}$ ) and (7h). Then the optimality conditions (7a) to $(7 \mathrm{~d})$ reduce to

$$
\begin{aligned}
& n_{1} E^{\prime}(B)-n_{1}(1+t) c_{1}^{\prime}\left(b^{u}\right)+\gamma_{2}\left[c_{2}^{\prime}\left(b^{u}\right)-c_{1}^{\prime}\left(b^{u}\right)\right]=0, \\
& n_{2} E^{\prime}(B)-n_{2}(1+t) c_{2}^{\prime}\left(b^{u}\right)-\gamma_{1}\left[c_{2}^{\prime}\left(b^{u}\right)-c_{1}^{\prime}\left(b^{u}\right)\right]=0 .
\end{aligned}
$$

Since $\gamma_{i}>0$ and $c_{2}^{\prime}(b)>c_{1}^{\prime}(b)$ for all $b>0$, we have $E^{\prime}(B)-(1+t) c_{1}^{\prime}\left(b^{u}\right)<0$ and $E^{\prime}(B)-(1+t) c_{2}^{\prime}\left(b^{u}\right)>0$. But this implies $c_{1}^{\prime}\left(b^{u}\right)>c_{2}^{\prime}\left(b^{u}\right)$, which is a contradiction. Therefore, the optimal policy cannot be uniform if $c_{2}\left(b_{2}^{c}\right)-c_{1}\left(b_{2}^{c}\right)>F_{1}-F_{2}$. This completes the proof of Subsect. 4.1.

\section{Appendix B}

Under asymmetric information, the first-best solution can be implemented if $\gamma_{1}=\gamma_{2}=0$ does not yield a contradiction in ( $7 \mathrm{a})-(7 \mathrm{~h})$. Noting that the first-best policy combinations 
satisfy $S_{i}^{c}=c_{i}\left(b_{i}^{c}\right)+F_{i}$ (because $\lambda_{i}>0$ ) for $i=1,2$, conditions (7g) and (7h) imply that the first best is incentive compatible only if

$$
c_{2}\left(b_{2}^{c}\right)-c_{1}\left(b_{2}^{c}\right) \leq F_{1}-F_{2} \leq c_{2}\left(b_{1}^{c}\right)-c_{1}\left(b_{1}^{c}\right) .
$$

Let us derive the second-best policy menu when $c_{2}\left(b_{2}^{c}\right)-c_{1}\left(b_{2}^{c}\right)>F_{1}-F_{2}$. The first-best solution with $\gamma_{1}=\gamma_{2}=0$ can not be implemented because $\gamma_{1}=0$ yields a contradiction: condition (7g) only holds if $c_{2}\left(b_{2}^{c}\right)-c_{1}\left(b_{2}^{c}\right)=F_{1}-F_{2}$. Therefore, we necessarily have $\gamma_{1}>0$ and $\gamma_{2} \geq 0$. Appendix A already proved that $\gamma_{1}>0$ and $\gamma_{2}>0$ is never optimal, which leaves us with the possibility that $\gamma_{1}>0, \gamma_{2}=0$. Condition (7d) implies that $\lambda_{2}=$ $\gamma_{1}+t n_{2}>0$. So, $\lambda_{2}>0$ and $\lambda_{1} \geq 0$. Now $\lambda_{1}>0, \lambda_{2}>0$ would imply $S_{i}=c_{i}\left(b_{i}\right)+F_{i}$ for $i=1,2$; see (7e) and (7f). And $\gamma_{1}>0$ implies $S_{1}-c_{1}\left(b_{1}\right)-S_{2}+c_{1}\left(b_{2}\right)=0$; see (7g). Combining the two results yields $F_{1}-c_{2}\left(b_{2}\right)-F_{2}+c_{1}\left(b_{2}\right)=0$, which contradicts $c_{2}\left(b_{2}^{c}\right)-c_{1}\left(b_{2}^{c}\right)>F_{1}-F_{2}$. That means that only $\lambda_{1}=0, \lambda_{2}>0$ is possible in the case $\gamma_{1}>0, \gamma_{2}=0$. Combining Equations 7 a to $7 d$, we obtain conditions (6a)-(6d).

An identical analysis for $F_{1}-F_{2}>c_{2}\left(b_{1}^{c}\right)-c_{1}\left(b_{1}^{c}\right)$ reveals that the only feasible set of Kuhn-Tucker multipliers is $\gamma_{1}=0, \gamma_{2}>0, \lambda_{1}>0, \lambda_{2}=0$. This is the exact same set of values for the Kuhn-Tucker parameters as for the case $c_{2}\left(b_{2}^{c}\right)-c_{1}\left(b_{2}^{c}\right)>F_{1}-F_{2}$, except that all subscripts " 1 " should now read " 2 ", and vice versa. That means that the first-order conditions obtained are the same as in (6a)-(6d), with all subscripts interchanged.

\section{References}

Boogerd A, Groenewegen P, Hisschemoller, M (1997) Knowledge utilization in water management in the Netherlands related to desiccation. Water Res Bull 33(4): 731-740

Dasgupta PS, Hammond PJ, Maskin ES (1979) The implementation of social choice rules: some results on incentive compatibility. Rev Econ Stud 46:185-216

di Corato L (2006) Mechanism design for biodiversity conservation in developing countries. Marco Fanno working paper 34, University of Padova, Padova

European Commission (2005) Agri-environment measures: overview on general principles, types of measures, and application European Commission, Directorate General for Agriculture and Rural Development, Brussels

Feldhammer GA, Gates JE, Harman DM, Loranger AJ, Dixon KR (1986) Effects of interstate highway fencing on white-tailed deer activity. J Wildl Manage 50:497-503

Ferraro PJ (2001) Global habitat protection: limitations of development interventions and a role for conservation performance contracts. Cons Biol 15(4):990-1000

Ferraro PJ (2008) Asymmetric information and contract design for payments for environmental services. Ecol Econ 65:810-821

Fritz H, Saïd S, Renaud PC, Mutake S, Coid C, Monicat F (2003) The effects of agricultural fields and human settlements on the use of rivers by wildlife in the mid-Zambezi valley, Zimbabwe. Landscape Ecol 18:293-302

Garrido A, Martínez-Santos P, Lucas MR (2006) Groundwater irrigation and its implications for water policy in semiarid countries: the Spanish experience. Hydrogeology J 14:340-349

Goeschl T, Lin T (2003) Conservation contracting under dual information asymmetry. Cambridge University, Cambridge, Unpublished manuscript

Goeschl T, Lin T (2004) Biodiversity conservation on private lands: information problems and regulatory choices. FEEM working paper 55.2004, Venice International University, Venice

Groves T (1973) Incentives in teams. Ectrica 41:617-631

Guesnerie R, Laffont JJ (1984) A complete solution to a class of principal-agent problems with an application to the control of a self-managed firm. J Publ Econ 25:329-369

Harris M, Townsend RM (1981) Resource allocation under asymmetric information. Ectrica 49:33-64

Jansen AJM, Grootjans AP, Jalink MH (2000) Hydrology of Dutch Cirsio-Molinietum meadows: prospects for restoration. Appl Veg Sc 3:51-64

Laffont JJ, Tirole J (1993) A theory of incentives in procurement and regulation. MIT Press, Cambridge 
Latacz-Lohmann U (2004) Dealing with limited information in designing and evaluating agri-environmental policy. Unpublished manuscript

Latacz-Lohmann U, Schilizzi S (2006) Auctions for conservation contracts: a review of the theoretical and empirical literature, Report to the Scottish Executive Environment and Rural Affairs Department

Llamas MR, Martínez-Santos P (2005) Intensive groundwater use: silent revolution and potential source of social conflict. J Water Resour Plann Manage 131(5):337-341

Macho-Stadler I, Pérez-Castrillo D (2001) An introduction to the economics of information: incentives and contracts, 2nd edn. Oxford University Press, Oxford

MacMillan D, Hanley N, Daw M (2004) Costs and benefits of wild goose conservation in Scotland. Biol Cons 119:475-485

Martínez-Santos P, Martínez-Alfaro PE (2010) Estimating groundwater withdrawals in areas of intensive agricultural pumping in central Spain. Agric Water Manage 98:172-181

Mew HE Jr, Medina MA Jr, Heath RC, Reckhow KH, Jacobs TL (1997) Cost-effective monitoring strategies to estimate mean water table depth. Ground Water 35(6):1089-1096

Mills J, Rook Aj, Dumont B, Isselstein J, Scimone M, Wallis De Vries MF (2007) Effect of livestock breed and grazing intensity on grazing sytems 5: management and policy. Grass Forage Sci 62(4):429-436

Mirrlees JA (1971) An exploration in the theory of optimal income taxation. Rev Econ Stud 38:175-208

Motte E, Salles JM, Thomas L (2004) Information asymmetry and incentive policies to farmers for conserving biodiversity in forested areas in developing countries. LAMETA, Montpellier, unpublished manuscript

Moxey A, White B, Ozanne A (1999) Efficient contract design for agri-environmental policy. J Agric Econ 50(2):187-202

Naidoo R, Balmford A, Ferraro PJ, Polasky S, Ricketts TH, Rouget M (2006) Integrating economic costs into conservation planning. Trends Ecol Evol 21(12):681-687

OECD (1997) The environmental effects of agricultural land diversion schemes. Organization for Economic Co-operation and Development, Paris

Ozanne A, Hogan T, Colman D (2001) Moral hazard, risk aversion and compliance monitoring in agri-environmental policy. Eur Rev Agric Econ 28:329-347

Papouchis CM, Singer FJ, Sloan WB (2001) Responses of desert Bighorn sheep to increased human recreation. J Wildl Manage 65(3):573-582

Peerlings J, Polman NBP (2004) Wildlife and landscape services production in Dutch dairy farming: jointness and transaction costs. Eur Rev Agric Econ 31(4):427-449

Post DM, Taylor JP, Kitchell JF, Olson MH, Schindler DE, Herwig BR (1998) The role of migratory waterfowl as nutrient vectors in a managed wetland. Cons Biol 12(4):910-920

Rolfe J, Windle J, McCosker J (2009) Testing and implementing the use of multiple bidding rounds in conservation auctions: a case study application. Can J Agric Econ 57(3):287-303

Romin LA, Bissonette JA (1996) Deer-vehicle collisions: status of state monitoring activities and mitigation efforts. Wildl Soc Bull 24(2):276-283

Smith RBW (1995) The conservation reserve program as a least-cost land retirement mechanism. Am J Agric Econ 77:93-105

Smith RBW, Tomasi TD (1995) Transaction costs and agricultural nonpoint-source pollution control policies. J Agric Res Econ 20(2):277-290

Smith RBW, Tomasi TD (1999) Multiple agents, and agricultural nonpoint-source water pollution control policies. Agric Res Econ Rev 28(1):37-43

Stoneham G, Chaudhri V, Ha A, Strappazzon L (2003) Auctions for conservation contracts: an empirical examination of Victoria's BushTender trial. Austr J Agric Res Econ 47(4):477-500

White B (2002) Designing voluntary agri-environmental policy with hidden information and hidden action: a note. J Agric Econ 53:353-360

Wu JJ, Babcock BA (1995) Optimal design of a voluntary green payment program under asymmetric information. J Agric Res Econ 20:316-327

Wu JJ, Babcock BA (1996) Contract design for the purchase of environmental goods from agriculture. Am J Agric Econ 78:935-945

Wunder S, Engel S, Pagiola S (2008) Taking stock: a comparative analysis of payments for environmental services programs in developed and developing countries. Ecol Econ 65:834-852 